\title{
How to design the metro network for maximal accessibility potential? A comparative analysis of Shanghai
}

\author{
Lingzhu Zhang, Alain Chiaradia \\ Faculty of Architecture, DUPAD, The University of Hong Kong \\ E-mail: zhanglz@hku.hk, alainjfc@hku.hk
}

\begin{abstract}
As metro systems become more extensive they also become more complex, an analysis of the network shape and structure can be of substantive help for planners at early design stages to effectively evaluate multiple alternatives. This study compares the design scenarios of adding a typical circular ring metro line versus a novel alternative using two overlapping ellipse metro line rings. Ring metro lines have been found to be an important factor in network topology and the improvement of metro system network efficiency and reliability. A ring metro line can improve the connectivity and directness of a metro system network and thus improve transit by reducing mean travel time. A highly concentrated and dense central core surrounded by remote residential neighbourhoods, a monocentric city, would make circumferential travel less effective than in larger polycentric city with several sub-regional centres. Using Shanghai metro system 2017 as baseline, we consider the novel morphological alternative scenario of two overlapping ellipses and compare its relative performance to the more traditional ring metro line, by using graph theoretical topological and Euclidean centrality measures, otherwise known as' closeness' or 'accessibility' or 'all to all' mean distance. The comparison between the two scenarios shows that the two overlapping ellipse scenario is better at minimizing mean Topological distance, Mean Euclidean distance is well-correlated to actual travel time, The two-ellipse scenario leads to a reduction of $8 \%$ of network mean topological distance, while a simple ring reduces it only by $0.13 \%$.
\end{abstract}

Keywords: Urban Morphology, Spatial Design Network Analysis, Metro Network, Accessibility, Shanghai.

\section{Introduction}

Major cities in China are building and expanding metro systems as a strategy to improve sustainable mobility and reduce the negative environmental and social consequences of fastpaced motorization (Zhuang \& Zhang, 2016). Chinese cities are leading in terms of the planning and construction of metro systems: 28 cities in China have metro networks, and metro systems are currently under construction in 16 additional cities ( $\mathrm{Lu}$, et al., 2016). In Shanghai, the high-capacity metro network plays an important role in the urban movement and urban morphology generating pattern. The Shang- hai Metro, started in 1993, is one of the fastest growing systems in the world. In 2017, there were 14 metro lines and 365 stations, with an operating route length of $617 \mathrm{~km}$, making it the longest metro in the world. In 2016, the annual ridership of the Shanghai Metro system was 3.4 billion, making it the second busiest metro system after the Beijing metro system. Although still in the planning stages, Shanghai expects to lay another $930 \mathrm{~km}$ of new metro track by 2040. As of 2017, Shanghai had more than $200 \mathrm{~km}$ of subway under construction. By the end of 2020, the network will comprise 18 lines spanning 800 kilometres. Are these plans effective and suited for the Shanghai region? 
For the assessment of transit networks, traditional contemporary travel forecasting models are data intensive using a large variety of variables including detailed socioeconomic variables (Bierlaire, et al., 2015). More recently, transportation infrastructure and urban form have been shown to also play a major role (Newman \& Kenworthy, 1991; Cervero \& Kockelman, 1997; Ewing \& Cervero, 2010). Both approaches require the use of detailed data sets that are not publicly available in China. In recent years, the literature has focused on the features of metro systems as a physical network with analysable geometric and topological features (Derrible \& Kennedy, 2009; 2010; 2011; Hadas \& Ceder, 2010; Roth, et al., 2012). The contemporary use of graph theory in network analysis started with communication networks (Shimbel, 1953) and transport networks (Garrison \& Marble, 1962; Kansky, 1963), and in accessibility analysis within network geography (Savigear, 1967; Haggett \& Chorley, 1969; Ingram, 1971), which is also called spatial separation (Pooler, 1995). In the last 15 years, this has been extended to systematic studies of metro network systems conducted for network analysis purposes that did not include boarding data (Gattuso \& Miriello, 2005), related to metro station entry and exit in London and Shanghai (Chiaradia, et al., 2005; Zhang, et al., 2015), and more systematically across multiple network with boarding data (Derrible \& Kennedy, 2009). Laporte et al. (1997) assessed three simple networks with star, triangle, and radial-ring configurations with similar total network lengths, similar numbers of stations, except for the triangular network. They compared different factors for metro networks performance such as directness and connectivity. In their study, a radial and ring network was the most performant. Vuchic (2005) classified transit lines and discussed the advantages and disadvantages of radial, diametrical, and ring lines. Radial lines traditionally address the heaviest travel demand from outer to inner city. Diametrical lines connect two outer city areas and pass through the city main centre. Ring lines are laid out around a city centre and intersect radial lines, allowing for transfers and thus constitute an integrated, multipath network. Ring lines improve con- nectivity between radial and diametrical lines, making travel time shorter by-passing the main centre, reducing congestion in the main centre while networking sub-centres, thus increasing sub-centre inter-accessibility. Ring lines are less usual in North American cities than in European and Asian cities (Saidi, et al., 2014). The reason may be due to the urban configuration of North American cities, which are mainly monocentric, whereas European and Asian cities, while also mostly monocentric, are exhibiting emerging or planned polycentrism (Vuchic, 2005; Saidi, et al., 2014). Some cities have more than one ring, these cities include London, Madrid, Tokyo and Beijing. Other cities such as Copenhagen, Boston, Paris, Washington and Chicago are considering ring lines (Saidi, et al., 2014). Shanghai also has a longterm plan to construct a second ring line (Jian, 2015). The main questions that arise with respect to ring lines are the following: Should a ring line be developed in a metro network? If so where? Is it possible to have more than one ring line? Does the ring line shape matter or not? For Shanghai, Saidi et al. (2016) give a positive answer to the first three questions. They suggest an optimal second ring line for the Shanghai metro system located between 10 and 11 kilometres from the central Shanghai.

The primary motivation for this paper is to offer a review of the ring scenario proposed by Saidi et al. (2016) in Shanghai to compare it to a novel alternative that combine two overlapping ellipse rings using graph theoretic topological/Euclidean performance indicators to assess the two scenarios. In the metro network analysis literature, the question of the shape of the ring is always assumed to be close to a circle. The hypothesis is that in Shanghai two overlapping ellipses (TOE) provide better performance than a simple ring controlling for network length and station number.

The paper is organised as follows. In the first section, we motivate the selection of the two overlapping ellipse rings as an alternative to a simple ring. In the second section, we give an overview of the Shanghai Metro system. The third section introduces a series of metro system graph theoretic performance indicators. In the fourth section, we present the analysis results of the evolution of Shanghai Metro sys- 
tem since 1993, the 2017 baseline, and the two scenarios: a ring line located $10-11 \mathrm{~km}$ from central Shanghai as proposed by Saidi et al. (2016) and the TOE scenario.

\section{Justification of the ellipse scenario}

Two morphological analyses support the justification of the TOE scenario: A shape index approach Shanghai region urban development gradients.

A shape index is a dimensionless index that describes shape compactness and captures partially its morphology. A circle has a shape index of 1 .

Shape Index $=$ perimeter $2 / 4 \pi *$ area) (eq. 1)

Kanga et al. (2012) showed that in 10 cities in China, at intra-urban level, with change in city size (small to large) and in city shape index (compact to dispersed), each individual citizen will need to travel farther daily, and vice versa. Nielsen et al. (2005) proposed a set of strat- egies to improve transit system performance. Two of these strategies are morphological: (i) adjusting the network to the urban structure to facilitate its legibility by the users; (ii) facilitating transfer to move away from the current many-to-many configuration to all-to-all configuration to favour the network effect (Mees, 2000). In Shanghai, urban development since 1995 has followed two gradients toward Hangzhou and toward Suzhou along the road corridors G15-G2 and S26-S58 (Cui \& Shi, 2012; Shi, et al., 2017). We propose that the two overlapping ellipse rings follow these gradients (See Figure 6b).

\section{Shanghai metro system network overview}

The changes between 1995 and 2017, of number of stations 1 and route length of the Shanghai Metro network are shown in Figure 1. The Shanghai metro network has grown rapidly since Line 1 opened in 1995 with an exponential increase in both number of stations and route length. During 1995 to 2005, the number of stations rose from 13 to 73 - a six-fold in-
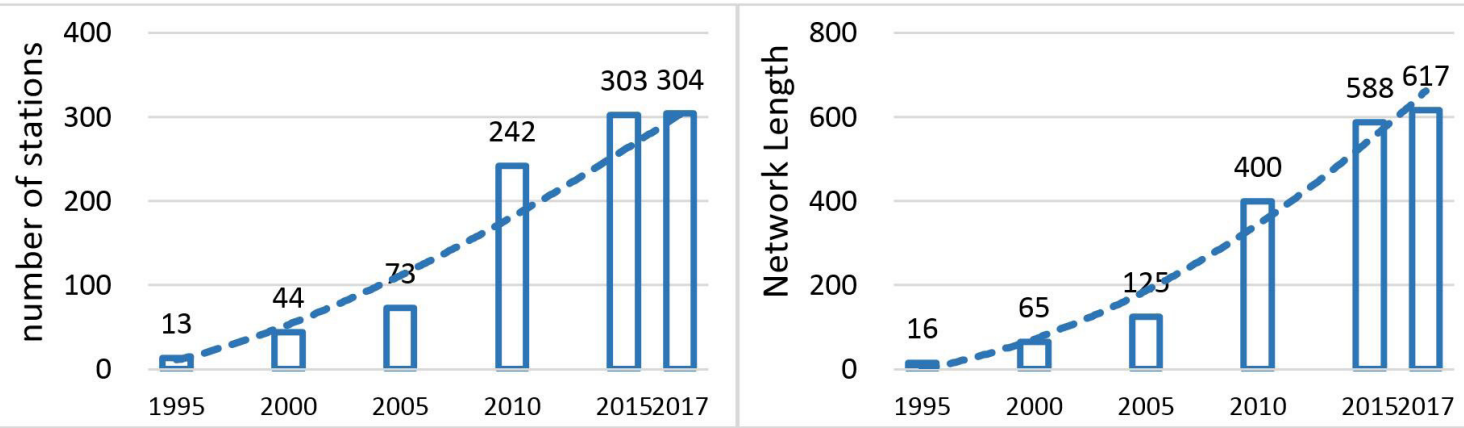

Figure 1. the evolution of Shanghai Metro Network 1995-2017, a) number of stations b) network length
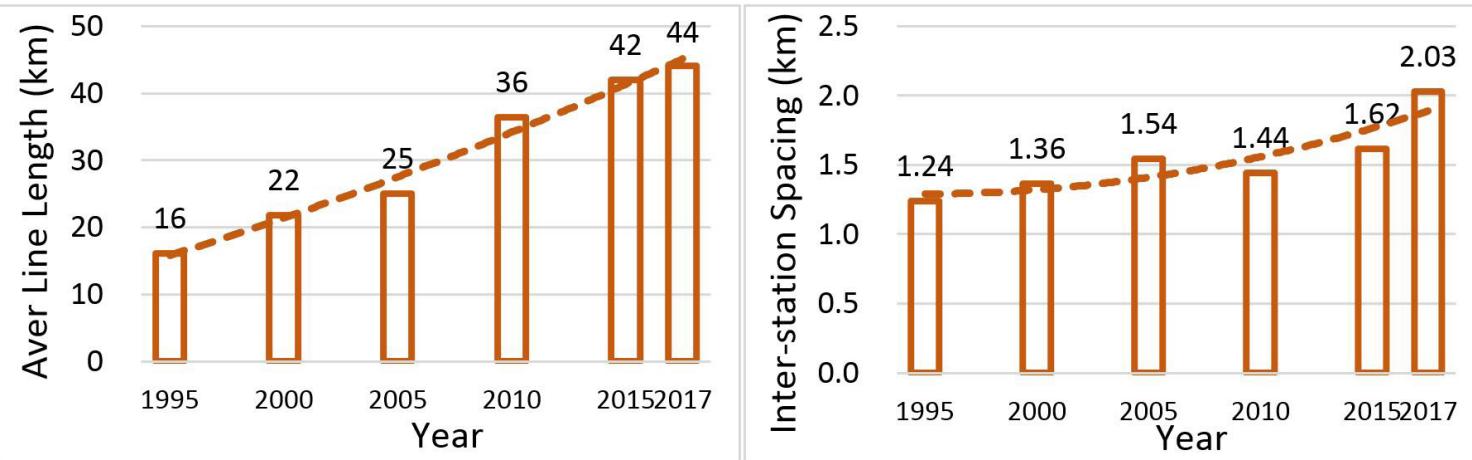

Figure 2. The evolution of average line length and inter-station spacing, 1995-2017 
crease in only 10 years, In the subsequent 12 years, the number of stations increased from 73 to 304 - a four-fold increase based on an already large base figure. During the same period, the total route length increased from only $16 \mathrm{~km}$ in 1995 to $617 \mathrm{~km}$ in 2017-a dramatic 40 -fold increase. The daily ridership in the same period skyrocketed from 240,000 to more than 10 million (Zhuang \& Zhang, 2016).

\section{Regional accessibility: Average Line Length \& Inter-station Spacing}

As network grew, so did the average line length and average inter-station spacing. As can be seen from Figure 2, from 1995 to 2017, the average line length of Shanghai metro network more than doubled, grew from $16 \mathrm{~km}$ to $44 \mathrm{~km}$ (an average annual increase of 5\%), and the inter-station spacing rose from $1.24 \mathrm{~km}$ in 1995 to $2.03 \mathrm{~km}$ in 2017 (an average annual increase of $2.3 \%$ ). Notably, since 2005, the metro system service has been extended to the suburban areas outside the city core. The average line length increased by $45 \%$ from 2005 to 2010 (from $25 \mathrm{~km}$ to $36 \mathrm{~km}$ ). This can be explained by the Shanghai 12th five-year urban public transport plan (from 2005-2010) announced in 2005 , in which the importance of metro was highlighted for the first time.

\section{Graph level indicators}

Derrible $(2010,2011)$ and Roth (2012) com- puted graph measure from a connectivity matrix which is not geographically spatialized. In this paper the Shanghai metro system geography was mapped with three elements:

- node - point representing the spatial positions where there is the access to the metro;

- line - sequence of links and nodes representing the routes;

- network - the set of nodes, links and lines.

Each transfer between two lines was considered as a topological distance of two thus added two short links2. A network was created to represent the metro lines network topology and geography using one link between each station. This mapping allow to compute not only topological graph measure but also Euclidean graph measure and as such better understand travel time.

\section{Ring line and TOE ring line scenarios for Shanghai Metro}

The Shanghai metro network uses a core ring (Inner ring Line 4) to encircle a core of stations which are characterized by higher line connectivity. Branches radiate from the core and reach outer areas of the urban system. The first ring line, the line 4 , is located near the Inner-ring Road.

The Shanghai government has proposed in Shanghai Master Plan 2016-2040 to construct a second ring-shaped metro line near Shanghai Middle Ring road (Figure 3-a) to improve the connectivity and directness of the metro system and thus improve transit by reducing mean

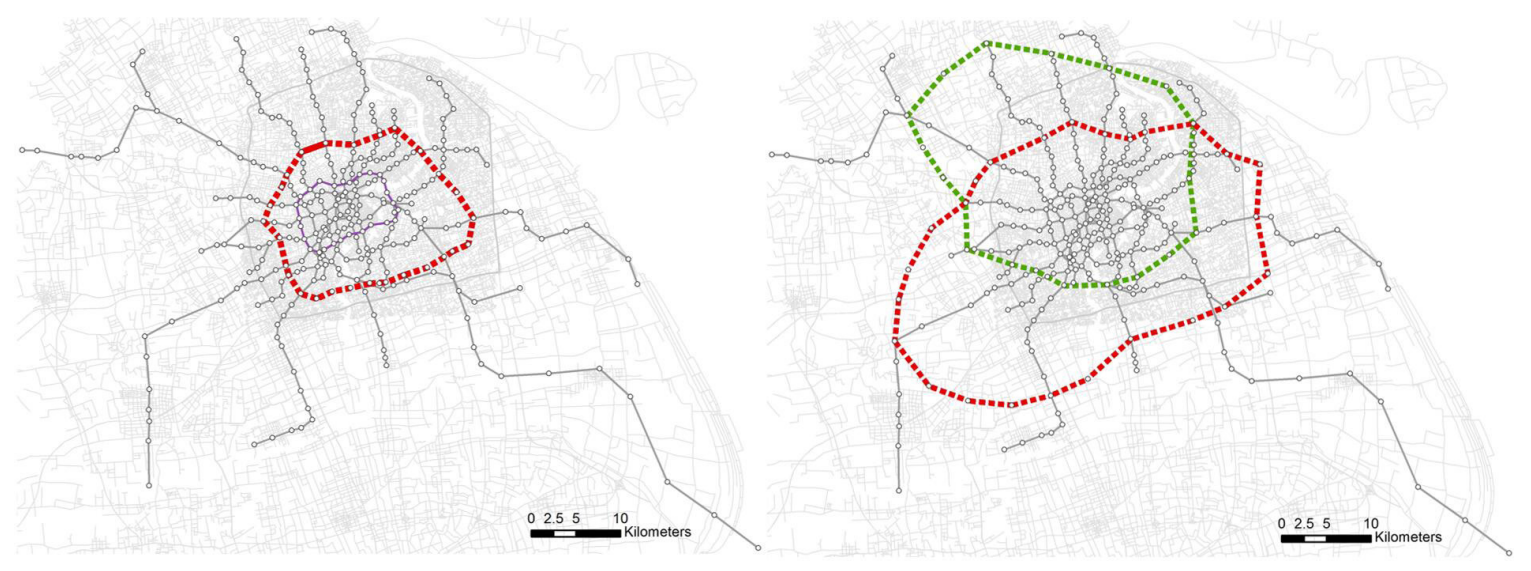

Figure 3. Recommended ring line scenario \& TOE scenario in Shanghai 
travel time. Using Shanghai metro system 2017 as baseline, we propose a novel morphological alternative scenario to the ring-shape scenario by using two overlapping ellipses (Figure 3-b). The TOE scenario locates as many metro stations as possible on the future City Subcenters 3 and extends the network to the west (Jiangsu) and the south (Zhejiang) to improve suburb-to-suburb connections.

\section{Graph theoretic metro network perfor- mance characterisation}

Derrible (2012) and Kennedy (2009) showed that network topologies play a key role in public transport ridership level. Saidi et al. (2014) showed the association between ring line ridership and density and line length. Chiaradia et al. (2005) were the first to use closeness centrality-accessibility to analyse the London Underground network. They found that topological configuration of the metro network can explain at least $50 \%$ of entry/exit movement at metro stations. A study of the Shanghai Metro system (Zhang, 2014) also showed that the accessibility values of metro network model are highly correlated with entry/exit movements. Shimbel (1953) suggested that one strategy for overall performance was to minimise mean path length. It is a measure of the efficiency of information or mass transport on a network.

\section{Closeness Centrality: Mean Distance (MCD)}

Spatial Design Network Analysis (Chiaradia, et al., 2014; Cooper, et al., 2014)4 (sDNA) was used to compute the closeness centrality of Shanghai metro networks. Closeness is a centrality measure which matches commonly held notions of accessibility. Closeness or accessibility is the Mean Distance from all to all. We use sDNA's Mean Custom (Topological) Distance (MCD) average number of link independently of their length and Mean Euclidean Distance (MED) to measure the network closeness (or farness) using distance.

$$
M C D(x)=\frac{\sum_{y \in R x} d_{C}(x, y) P(y)}{\sum_{y \in R_{x}} P(y)}
$$

Eq. 2

where $\operatorname{MCD}(\mathrm{x})$ is the Mean Custom (Topological) Distance for link $\mathrm{x}, y \in \mathrm{Rx}_{\text {is }}$ each other link $\mathrm{y}$ in $\mathrm{Rx}$ the radius surrounding $\mathrm{x}, \mathrm{d}_{\mathrm{c}}(\mathrm{x}, \mathrm{y})$ is the shortest possible topological distance along a route from $\mathrm{x}$ to $\mathrm{y}$, and $\mathrm{P}(\mathrm{y})$ is the proportion of $y$ falling within the radius.
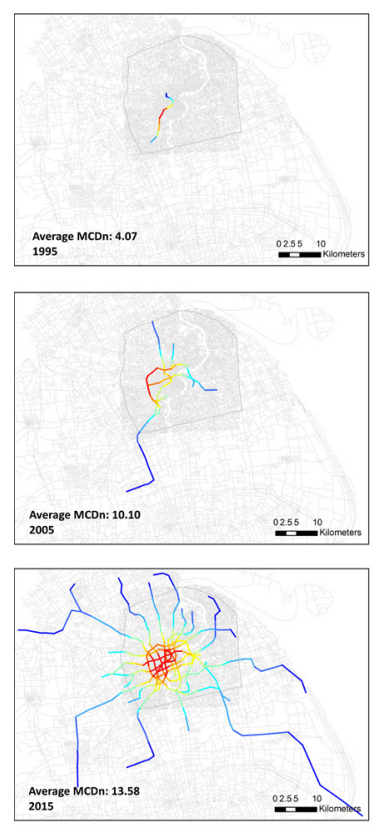
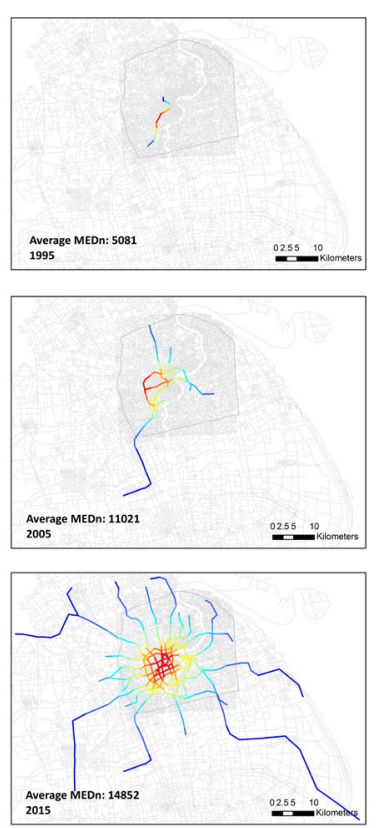
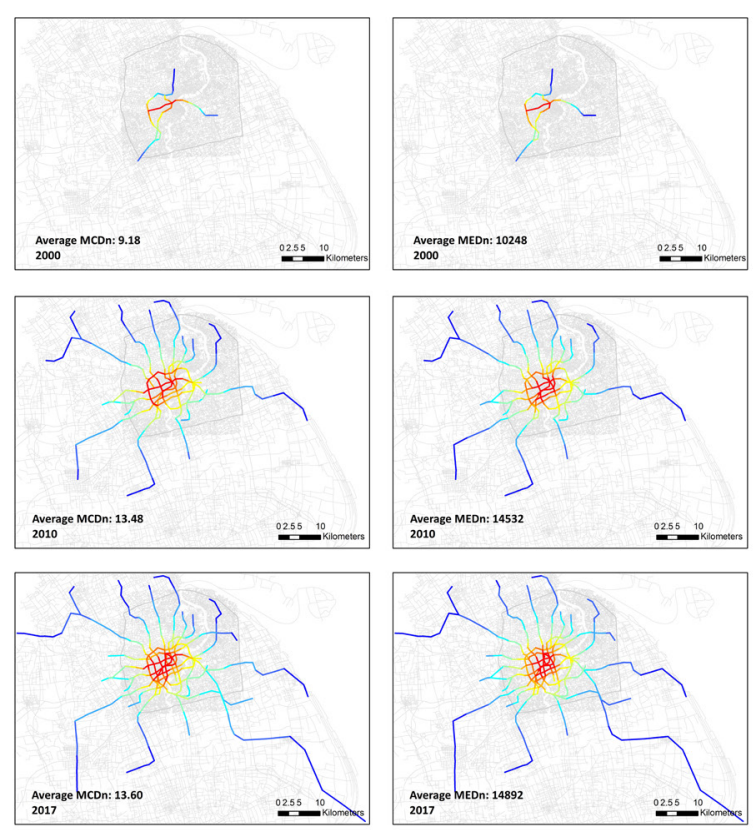

Figure 4. Shanghai metro geography, evolution 1993-2017 of Closeness Centrality (topological) 

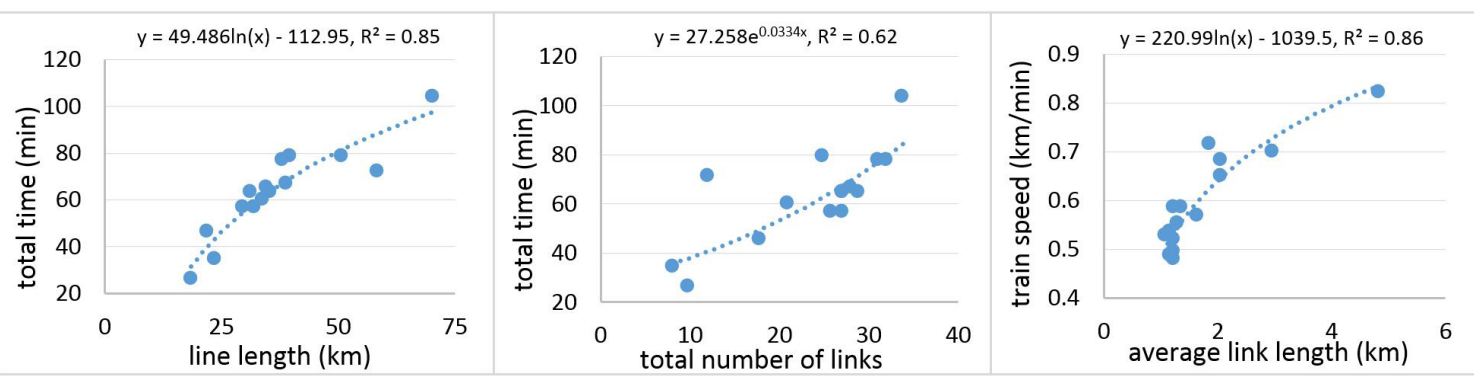

Figure 5. scatter grams showing the characteristics of existing 15 lines (line 1 to line 13, line

2 extension, line 16) : line length against total time taken between the two ends (a), total number of links against total time taken between

\begin{tabular}{|c|c|c|c|c|c|c|c|c|}
\hline \multirow[b]{2}{*}{ Network } & \multirow[b]{2}{*}{$\begin{array}{l}\text { Station } \\
\text { Number }\end{array}$} & \multirow[b]{2}{*}{$\begin{array}{l}\text { Link } \\
\text { Number }\end{array}$} & \multirow[b]{2}{*}{$\begin{array}{l}\text { Transfer } \\
\text { Station }\end{array}$} & \multirow[b]{2}{*}{$\begin{array}{l}\text { Total network } \\
\text { length }\end{array}$} & \multicolumn{2}{|c|}{ Regional Accessibility } & \multicolumn{2}{|c|}{ Closeness } \\
\hline & & & & & $\begin{array}{l}\text { Aver Line } \\
\text { length }(\mathrm{km})\end{array}$ & $\begin{array}{l}\text { Inter-station } \\
\text { spacing }(\mathrm{km})\end{array}$ & MCDn & MEDn \\
\hline 2017 baseline & 304 & 361 & $54(18 \%)$ & 617 & 44.07 & 2.02 & 13.60 & 14892 \\
\hline Scenario $\mathbf{R}$ & 313 & $390(8 \%)$ & $72(23 \%)$ & $695(17 \%)$ & $46.30(5 \%)$ & $2.22(10 \%)$ & 13.58 & 15302 \\
\hline Scenario TOE & 320 & $404(12 \%)$ & $77(24 \%)$ & $848(37 \%)$ & $52.99(20 \%)$ & $2.65(31 \%)$ & 12.59 & 17149 \\
\hline
\end{tabular}

Table 1: Summary of results

$\operatorname{MED}(\boldsymbol{x})=\frac{\sum_{y \in R x} d_{E}(x, y) p(y)}{\sum_{y \in R x} P(y)}$

Eq. 3

where $\operatorname{MED}(\mathrm{x})$ is the Mean Euclidean Distance for link $\mathrm{x}$, and $\mathrm{d}_{\mathrm{E}}(\mathrm{x}, \mathrm{y})$ is the shortest possible Euclidean distance along a route from $\mathrm{x}$ to $\mathrm{y}$.

Mean distance measures the ease of navigating to all possible destinations in radius $\mathrm{x}$ from each link. Lower values of mean distance indicate more direct (topological) or shorter paths to destinations within the radius. Table 1 below summarise the analysis results.

\section{Results and Discussion}

Topological and Euclidean closeness centrality measures for the network between 1993 to 2017 was computed by sDNA, divided into 10 quantiles and mapped in Figure 4. The Topological closeness measure (MCDn) rose from 4.07 in 1995 to 13.6 in 2017 - a 3.3-fold increase, and the Euclidean closeness measure (MEDn) rose from 5,081 to 14,892 - a 2.9-fold increase. The expansion of metro network has reduced the directness and increased the average mean length of trips.
Compared with the 2017 baseline, both Scenario $\mathrm{R}$ and Scenario TOE see a notable increase of number of transfer stations for; the number of transfer stations changes from 54 to 72 (an increase of 33\%) for Scenario R and to 77 for Scenario TOE (an increase of $43 \%$ ), corresponding to only $3 \%$ and $5 \%$ increase of total number of stations. An earlier study (Derrible $S, 2010$ ) showed that few transfer stations tend to retain a "monopole" on transferring in metros, therefore, both networks have good performance on maximizing number of transfer stations.

Compared with the 2017 baseline, both scenarios connect the outer stations together and to the city core, yet increase average line length and distance between metro stations. Both measures for scenario TOE (increased by $14 \%$ and $19 \%$ ) are higher than scenario R's (increased by 5\% and 9\%), thus scenario TOE provides higher regional accessibility.

The comparison of MCD values shows that TOE scenario works better for minimizing mean topological distance than Scenario R. The TOE scenario has a reduction of $7.94 \%$ (falls from 13.6 to 12.59) of network mean distance, while $\mathrm{R}$ scenario plan reduces only $0.13 \%$ (falls from 13.6 to 13.58 ).

Considering that the MCDn increased year 
by year in the last 2 decades, it would be especially meaningful to get a lower value by adding the two overlapping ellipse rings.

If we compare MCD to MED the finding is reversed. TOE scenario increase MED by $15 \%$ while R scenario increase it by only $3 \%$ yet given that the TOE scenario increase network length by $37 \%$ compared to $17 \%$ for the R scenario, adding twice the length of the R scenario increase MED moderately. As MCD (topological) does not account in link length difference we analyse the MED relationship with travel time.

Figure 5-a shows a strong correlation $(\mathrm{r} 2=0.85)$ between metro line length and total time taken between the two ends. Figure 5-b shows a significant correlation $(\mathrm{r} 2=0.621)$ between total number of links for each line and total time. Figure 5-c shows that speed increase as link length increase.

We can conclude that, for MCD is less related to travel time and that MED is better related to travel time. As the TOE scenario has an average link length of $4.85 \mathrm{~km}$ it would run about $22 \%$ faster than scenario $\mathrm{R}$ which has an average link length of $2.47 \mathrm{~km}$. Therefore, although TOE scenario has a 12 percent higher MED than the $\mathrm{R}$ scenario $(17,149$ versus 15,302 , Table 1), while the speed on the TOE will be about $22 \%$ higher than on the $\mathrm{R}$, the travel time accessibility should be enhanced overall.

\section{Conclusion}

In this study, we used a set of indicators to characterize the Shanghai metro system network: regional accessibility and closeness centrality. By looking at the Shanghai metro network from 1995 to 2017, we found that, as the network grew, regional accessibility (average line length $\&$ average inter-station spacing) both rose rapidly. However, the mean distance of the network had also a notable increase during the same period, that journeys became longer in general.

Using 2017 as baseline, two strategic network long-term planning extension scenarios of the Shanghai metro system network were assessed: one with a second ring-shaped (R) metro line running concentric with the existing ring line, the other with two overlapping ellipses (TOE) metro lines. A comparative analysis showed that, both scenarios increase significantly the number of stations, route length, and transfer station ratio compared with 2017 baseline. The regional accessibility values and closeness centrality analysis indicated that Scenario TOE works better for maximizing the suburban accessibility and minimizing average trip distance than Scenario R. The two overlapping ellipse rings should be tested as proposals with other transit systems in the world to investigate the ring line shape factor impact on metro system performance. This analysis is especially useful at the strategic conceptual planning phase, to test different network design scenarios alongside conventional transport planning tools.

Authors' contributions: LZ performed the network analysis, wrote the first draft of the paper. AC provided the original concept for the paper and the sDNA software. AC did and wrote the literature review and assisted with contextualisation of results. Both authors edited and approved the final version.

\section{Notes}

1. Transfer stations are not double-counted.

2. This approach was taken because some limited market research (REF) has shown that given a choice between alternative routes to the same destination with one line change at station level, passengers chose to switch to the route with the change if the difference in number of stations between the routes was at least two. This makes the effective cost of line change equal to two more metro stops.

3. According to the Shanghai Urban Master Plan 2016-2040 which was announced in 2016. 4. sDNA (Spatial Design Network Analysis) is a plugin for ArcGIS, Autocad, and open source GIS (QGIS) it uses the Shapefile (.shp) or .gdb files and link/node standard to analyze the spatial networks design characteristics using centrality measures and other measures such as severance. It provides many control variables. The software is freely available after registration at www.cardiff.ac.uk/sdna/with full specifications. 


\section{References}

Arbour \& Associés (2001) Faubourg Québec, paramètres de développement urbain (Société de développement de Montréal, Montréal).

Bierlaire, M., de Palma, A., Hurtubia, R. \& Waddell, P. eds., 2015. Integrated Transport and Land Use Modeling for Sustainable Cities. Lausanne: EPFL Press..

Cervero, R. \& Kockelman, K., 1997. Travel demand and the 3Ds: Density, diversity, and design. Transportation Research Part D: Transport and Environment, 2(3), pp. 199219.

Chiaradia, A., Crispin, C. \& Webster, C., 2014. sDNA a software for spatial design network analysis. [Online]

Available at: www.cardiff.ac.uk/sdna/

[Accessed 15 June 2014].

Chiaradia, A. J. F., Moreau, E. \& Raford, N., 2005. Configurational Exploration of Public Transport Movement Networks: A Case Study, The London Underground. Delft, Proceedings of the 5th Space Syntax Symposium, Techne Press.

Cooper, C., Chiaradia, A. \& Webster, C., 2014. Spatial Design Network Analysis(+). [Online]

Available at: www.cardiff.ac.uk/sdna/

[Accessed 16 June 2014].

Cui, L. \& Shi, J., 2012. Urbanization and its environmental effects in Shanghai, China. Urban Climate, Volume 2, pp. 1-15.

Derrible, S., 2012. Network Centrality of Metro Systems. Plus One, 7(7), p. e40575.

Derrible, S. \& Kennedy, C., 2009. Network Analysis of World Subway Systems Using Updated Graph Theory. Transportation Research Record: Journal of the Transportation Research Board, Volume 2112, p. 7-25..

Derrible, S. \& Kennedy, C., 2010. Characterizing metro networks: state, form, and structure. Transportation, 37(2), p. 275297.

Derrible, S. \& Kennedy, C., 2011. Applications of Graph Theory and Network Science to Transit Network Design. Transport Reviews, 31(4), pp. 495-519.
Ewing, R. \& Cervero, R., 2010. Travel and the Built Environment. Journal of the American Planning Association, 76(3), pp. 265-294.

Garrison, W. L. \& Marble, D. F., 1962. The Structure of Transportation Networks. Evanston, IL: Transportation Center Northwestern University)..

Gattuso, D. \& Miriello, E., 2005. Compared Analysis of Metro Networks Supported by Graph Theory. Networks and Spatial Economics, 5(4), pp. 395-414.

Hadas, Y. \& Ceder, A., 2010. Public Transit Network Connectivity, Spatial-Based Performance Indicators. Transportation Research Record: Journal of the Transportation Research Board, Volume 2143, pp. 1-8.

Haggett, P. \& Chorley, R. J., 1969. Network Analysis in Geography. London(UK): Hodder \& Stoughton Educational.

Ingram, D. R., 1971. The concept of accessibility: a search for an operational form. Regional Studies, 5(2), pp. 101-107.

Jian, Y., 2015. City may have a second ringline subway to alleviate traffic pressure: Metro planner. [Online]

Available at: http://www.shanghaidaily.com/ metro/City-may-have-a-second-ringlinesubway-to-alleviate-traffic-pressure-Metroplanner/shdaily.shtml

[Accessed 0106 2017].

Kanga, C., Mab, X., Tongc, T. \& Liu, Y., 2012. Intra-urban human mobility patterns: An urban morphology perspective. Physica A: Statistical Mechanics and its Applications, 391(4), p. 1702-1717.

Kansky, K. J., 1963. Structure of transport networks: relationships between network geometry and regional characteristics, Chicago: University of Chicago.

Laporte, G., Mesa, J. \& Ortega, F., 1997. Assessing the efficiency of rapid transit configurations. Top, 5(1), pp. 95-104.

Lu, K., Han, B., Lu, F. \& Wang, Z., 2016. Urban Rail Transit in China: Progress Report and Analysis (2008-2015). Urban Rail Transit, 2(3-4), pp. 93-105.

Mees, P., 2000. A Very Public Solution: Transport in the Dispersed City. Melbourne: Melbourne University Press. 
Newman, P. W. G. \& Kenworthy, J. R., 1991. (1991) Transport and urban form in thirtytwo of the world's principal cities. Transport Reviews: A Transnational Transdisciplinary Journal, 11(3), pp. 249-272.

Nielsen, G. et al., 2005. Public Transport Planning the Networks, Stavanger, Norway: HiTrans Best Practice Guide, vol. 2..

Pooler, J. A., 1995. The use of spatial separation in the measurement of transportation accessibility. Transport Research A: Policy and Practice, 29(6), pp. 421-427.

Roth, C., Kang, S. M., Batty, M. \& Barthelemy, M., 2012. A long-time limit for world subway networks. Journal of the Royal Society Interface, pp. 1-11.

Saidi, S. et al., 2016. Planning Urban Ring Rail Transit Lines, Case Study of Shanghai, China. Transportation Research Record: Journal of the Transportation Research Board, Volume 2540, pp. 56-65.

Saidi, S., Wirasinghe, S. C. \& Kattan, K., 2014. Rail transit, Exploration with Emphasis on Networks with Ring Lines. Transportation Research Record: Journal of the Transportation Research Board, Volume 2419, pp. 23-32.

Savigear, F., 1967. A Quantitative Measure of Accessibility. Town Planning Review, Volume 38, pp. 64-72.

Shimbel, A., 1953. Structural parameters of communication networks. The bulletin of mathematical biophysics, 15(4), pp. 501507.

Shi, Y., Wu, J. \& Shi, S., 2017. Study of the Simulated Expansion Boundary of Construction Land in Shanghai Based on a SLEUTH Model. Sustainability, 9(876), pp. $1-15$.

Vuchic, V., 2005. Urban Transit Operations, Planning and Economics. Hoboken, N. J.: John Wiley \& Sons, Inc.

Zhang, L., Chiaradia, A. \& Zhuang, Y., 2015. A Configurational Accessibility Study of Road and Metro Network in Shanghai, China. In: Q. Pan \& J. Cao, eds. Recent Developments in Chinese Urban Planning - Selected Papers from the 8th International Association for China Planning Conference, Guangzhou, China, June 21 - 22, 2014. English \& Chinese ed. Cham: Springer International Publishing, pp. 219-245. 